\title{
Liquid Crystalline Cholesteric Reflective Layers for Colored Silicon-Based Solar Cells
}

\author{
Sangwok Bae, Dong-Sun Park and Suk-Won Choi *(D)
}

check for updates

Citation: Bae, S.; Park, D.-S.; Choi, S.-W. Liquid Crystalline Cholesteric Reflective Layers for Colored Silicon-Based Solar Cells. Crystals 2021, 11, 1336. https://doi.org/ $10.3390 /$ cryst11111336

Academic Editor: Saripally Sudhaker Reddy

Received: 14 October 2021

Accepted: 30 October 2021

Published: 1 November 2021

Publisher's Note: MDPI stays neutral with regard to jurisdictional claims in published maps and institutional affiliations.

Copyright: (c) 2021 by the authors. Licensee MDPI, Basel, Switzerland. This article is an open access article distributed under the terms and conditions of the Creative Commons Attribution (CC BY) license (https:/ / creativecommons.org/licenses/by/ $4.0 /)$.
Department of Advanced Materials Engineering for Information \& Electronics, and Integrated Education, Institute for Frontier Science \& Technology (BK21 Four), Kyung Hee University, Yongin 17104, Korea; lfcbae007@khu.ac.kr (S.B.); ehdtjs1323@khu.ac.kr (D.-S.P.)

* Correspondence: schoi@khu.ac.kr; Tel.: +82-31-201-2256

\begin{abstract}
The performance of a prototype opaque-type colored silicon-based solar cell integrated with liquid crystalline cholesteric layers is investigated. These devices were developed using only organic components and wet processes, without complicated vacuum processes. The evaluated performances of the prototype solar cells were inferior to those of the other types of previously reported colored solar cells because of the inherent limitations of the cholesteric layers, such as the limited reflectance $(\sim 50 \%)$, narrow color gamut, and viewing angle-dependent color changes. We propose effective strategies for improving the performance of colored solar cell modules integrated with cholesteric layers.
\end{abstract}

Keywords: liquid crystals; cholesteric; photovoltaic; solar cells

Photovoltaic solar cells (SCs) are environment-friendly energy generation devices that have attracted global attention as a solution to environmental issues arising from the use of fossil fuels [1]. Recently, the concept of building-integrated photovoltaics (BIPVs) [2] has been proposed to realize ultimate energy harvesting, thus achieving netzero energy consumption [3-5]. For BIPV applications, SCs should cover all installable areas on building exteriors, such as windows, rooftops, and facades [6]. Because the colors of building exteriors strongly affect the esthetic and artistic impressions of cities, the color of the SCs is important for BIPV applications [4].

Colored SCs can be categorized into two types: Semitransparent and opaque. In general, semitransparent-colored SCs can be realized by tuning the absorbance of the photoactive layer of the SCs. Thus, SCs such as organic PVs and perovskites can readily tune the absorbance of the photoactive layer. These types of SCs have focused applications such as in energy-harvesting windows and glass roofs [7-10]. Compared to the conventional uncolored black SCs, these semitransparent ones inevitably exhibit a significant power conversion efficiency (PCE) loss owing to the absorbance tuning of their photoactive layers. However, for applications on rooftops and building walls, mainly silicon-based and high-efficiency opaque-type SCs are expected to be used [11].

Opaque SCs with a colorful appearance can be realized by integrating external colored or nanostructured layers with standard SCs $[4,12,13]$. For example, colored opaque SCs were demonstrated by attaching plasmonic color filters, consisting of an array of metallic subwavelength nanowires, on a transparent substrate of opaque SCs [13]. The reflective colors were modulated by the thickness or width of the metal gratings. Similarly, colored SCs attached to one-dimensional (1D) multi-nanolayered oxide reflective filters of opaque SCs have been reported [4]. These studies motivated us to explore colored opaque SCs with a color filter composed of liquid crystalline materials. In this study, we fabricated a prototype version of colored silicon-based SCs by integrating a reflective color layer using liquid crystalline cholesteric $(\mathrm{Ch})$ phases and performed feasibility tests on these devices. These colored SCs were developed using only organic components and wet processes, 
and no complicated vacuum process was employed contrary to the previously reported 1D photonic crystal layer fabrication method. The liquid crystalline $\mathrm{Ch}$ phases display a periodic structure originating from self-assembled helical structures and, consequently, can be considered as $1 \mathrm{D}$ photonic crystals $[14,15]$. Such $\mathrm{Ch}$ phases selectively reflect circularly polarized light (CPL) with the same handedness as that shown by helical structures. Therefore, within the reflective bandwidth, the Ch phase with right (left)-handed helicoidal structures transmits the left (right)-handed CPL and reflects the right (left)-handed CPL, as illustrated in Figure 1. The selectively reflected light within the reflective bandwidth was observed as colors [16]. Owing to these phenomena, the liquid crystal $\mathrm{Ch}$ phases can be used as reflective color filters.

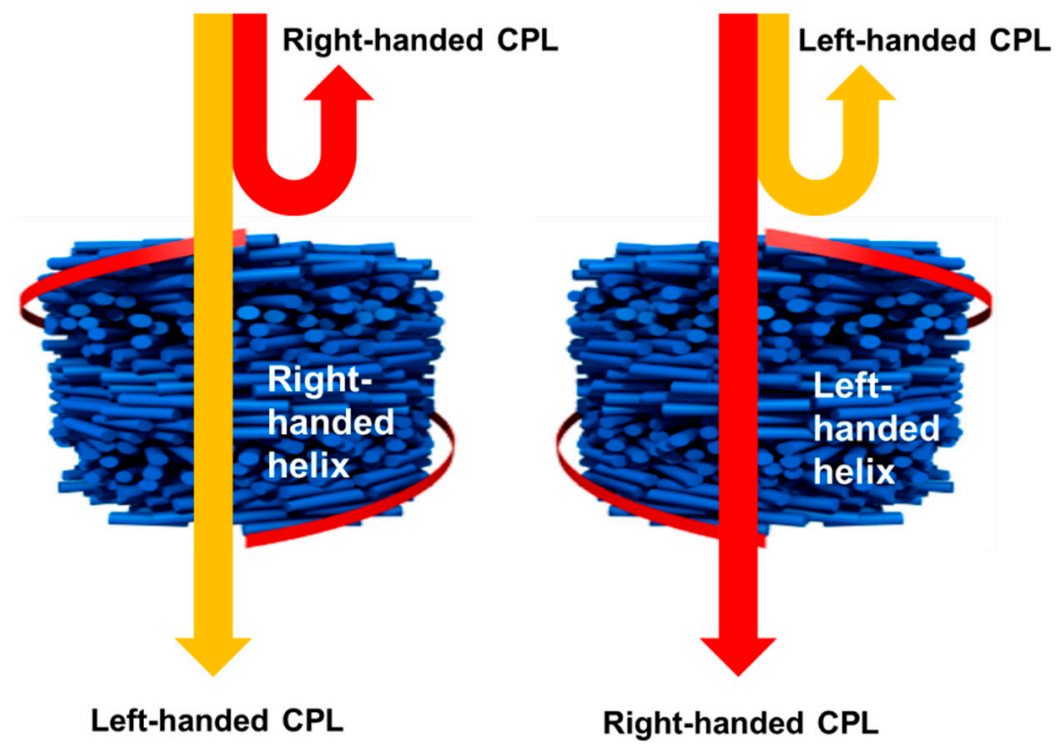

Figure 1. Illustration of the reflective and transmissive optical characteristics of $\mathrm{Ch}$ phases.

First, three colored Ch mixtures were fabricated by doping a chiral dopant (Iso$(6 \mathrm{OBA})_{2}$ [17], synthesized in our laboratory) in a calamitic nematic liquid crystal (NLC) mixture (HTW109100-100, HCCH). The host NLC showed the following phase sequence during the heating process: Crystal $\left(-40^{\circ} \mathrm{C}\right)$ nematic $\left(112^{\circ}\right)$ isotropic liquid. Red (R), green $(\mathrm{G})$, and blue (B) colored $\mathrm{Ch}$ mixtures were obtained by blending the NLC mixture with $4.9,5.5$, and $6.4 \mathrm{wt} \%$ chiral dopants, respectively. All the prepared $\mathrm{Ch}$ mixtures exhibited a $\mathrm{Ch}$ phase below $105^{\circ} \mathrm{C}$. The $\mathrm{Ch}$ mixtures were injected into sandwiched cells (cell gaps: $10 \mu \mathrm{m})$ comprising two glass substrates. To realize planar alignment in the Ch phases, the glass substrates were subjected to surface rubbing processes. Figure 2a shows the typical polarized optical microscopy images of the R, G, and B Ch layers, captured in the reflective mode. As shown in Figure 2a, the "oily streak" defects indicate planar textures in the R, $\mathrm{G}$, and $\mathrm{B}$ Ch layers. Figure $2 \mathrm{~b}$ shows the typical reflectance curves for the $\mathrm{G}$ Ch layers, obtained at different temperatures. The reflectance curves for the R, G, and B Ch layers exhibited constant profiles within the evaluated temperature range $\left(25-65^{\circ} \mathrm{C}\right)$, as shown in Figure $2 b$. These phenomena were produced by the host NLC mixture that exhibited a wide temperature range of the nematic phase and the constant birefringence within the nematic phase. The reflectance spectra exhibited a full width at half maximum (FWHM) of $75-90 \mathrm{~nm}$, and the peak wavelengths of the R, G, and B Ch layers were 650, 540, and $465 \mathrm{~nm}$, respectively. All the $\mathrm{R}, \mathrm{G}$, and $\mathrm{B} C \mathrm{Ch}$ layers showed $\sim 50 \%$ reflectance at their respective peak wavelengths. Figure $2 \mathrm{c}$ shows the color coordinates of the reflectance spectra of the fabricated R, G, and B Ch layers. The color gamut of the fabricated R, G, and B Ch layers was narrow because of the limited reflectance $(\sim 50 \%)$ and wide FWHM. 
a)
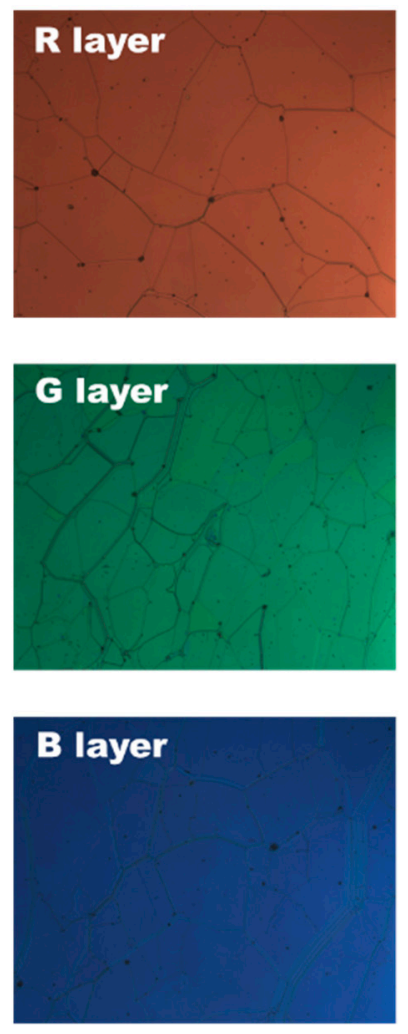

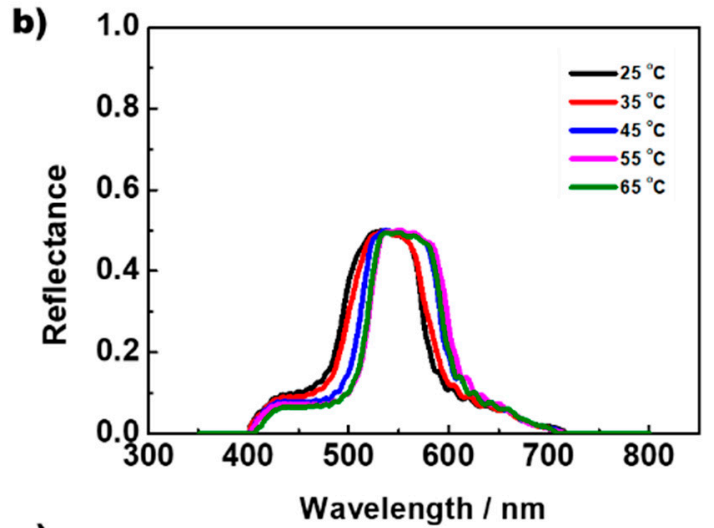

c)

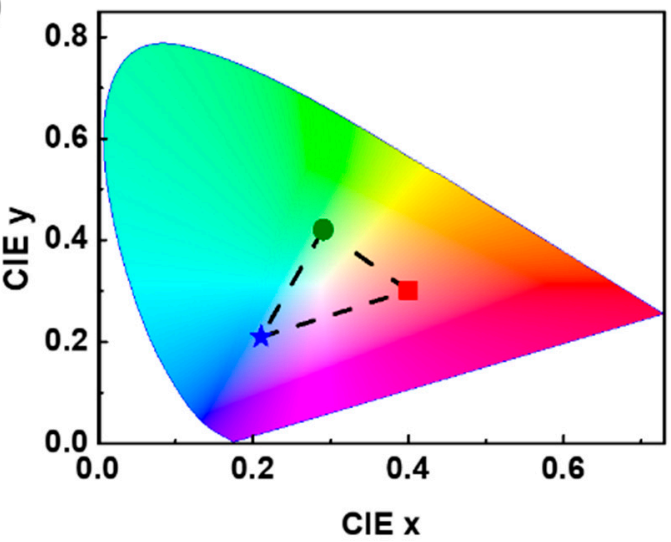

Figure 2. (a) Typical polarized optical microscopy images of the red (R), green (G), and blue (B) Ch layers. The images were captured in the reflective mode. (b) Typical reflectance curves for the $G$ Ch layers, obtained at different temperatures. (c) Color coordinates of the reflectance spectra of the fabricated R, G, and B Ch layers. Here, the reflectance spectra of the fabricated R, G, and B Ch layers were obtained by illuminating the layers with normally incident light.

Figure 3 shows the gradual changes in the reflective spectra of the R, G, and B Ch layers with an increasing viewing angle. In general, 1D phonic crystals change their reflective color when the viewing angle is changed. Therefore, all the spectra were blue-shifted at higher viewing angles, resulting in the realization of iridescence. However, the reflective color change at different viewing angles is not always desirable from an esthetic viewpoint when $\mathrm{Ch}$ reflective filters are used in BIPVs. Thus, for utilizing Ch layers as reflective filters, addressing the associated drawbacks such as the limited reflectance, narrow color gamut, and viewing angle dependence of the reflective colors is critical.
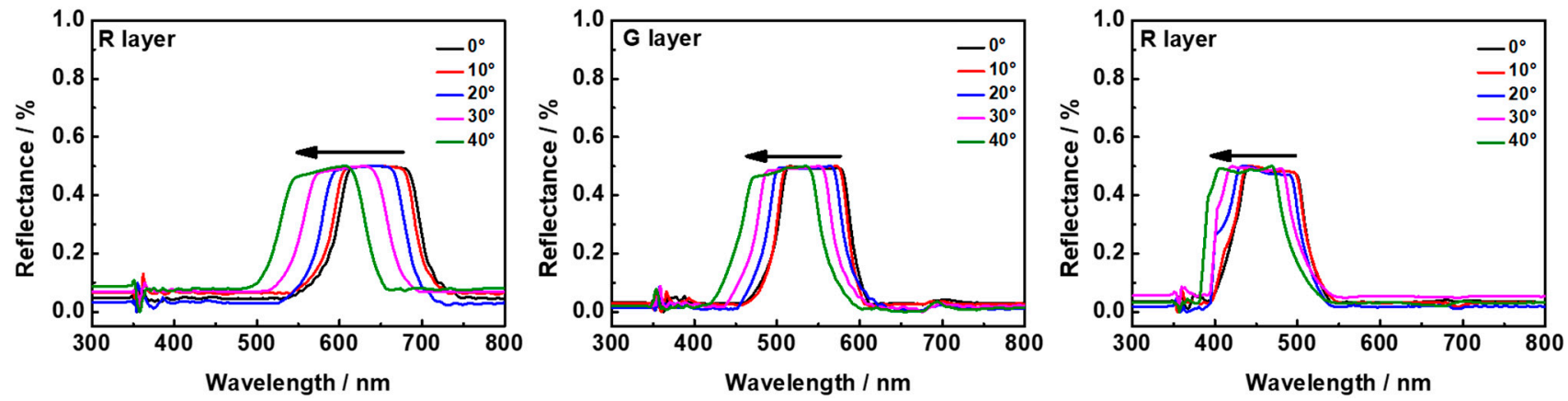

Figure 3. Reflectance spectra of the red (R), green (G), and blue (B) Ch layers with an increasing viewing angle.

Subsequently, we integrated the film with a commercially available silicon-based SC module (itemSchool) to investigate the applicability of the fabricated R, G, and B Ch 
layers in colored SC modules. To evaluate the device performance, we prepared four modules: SC-Ref and three colored SCs (SC-R, SC-G, and SC-B). Schematic illustrations of the four modules are presented in Figure 4a. SC-Ref, encapsulated on a printed circuit board together with a glass cover substrate (refractive index, $n=1.55$ ), was the reference module without the fabricated Ch layers. SC-R, SC-G, and SC-B were the silicon-based SC modules with R, G, and B Ch layers, respectively, integrated onto their front surface using a refractive index-matching fluid $(n=1.56)$. The device performance was evaluated against that of SC-Ref using a solar simulator under AM $1.5 \mathrm{G}$ conditions $\left(100 \mathrm{mWm}^{-2}\right)$ with a scan rate of $50 \mathrm{mV} \mathrm{s}^{-1}$ and scan step of $10 \mathrm{mV}$ at room temperature and relative humidity of $35 \%$. The typical current-voltage (J-V) curves are shown in Figure $4 \mathrm{~b}$, along with the transmittance curves of the fabricated R, G, and B Ch layers in the inset. The open-circuit voltage $\left(V_{o c}\right)$, short-circuit current density $\left(J_{s c}\right)$, fill factor $(F F)$, and PCE of the four SC modules are summarized in Table 1.

a)

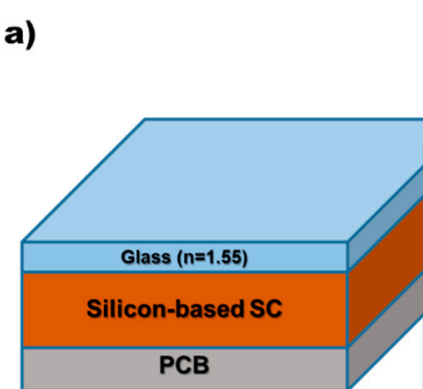

SC-Ref

b)

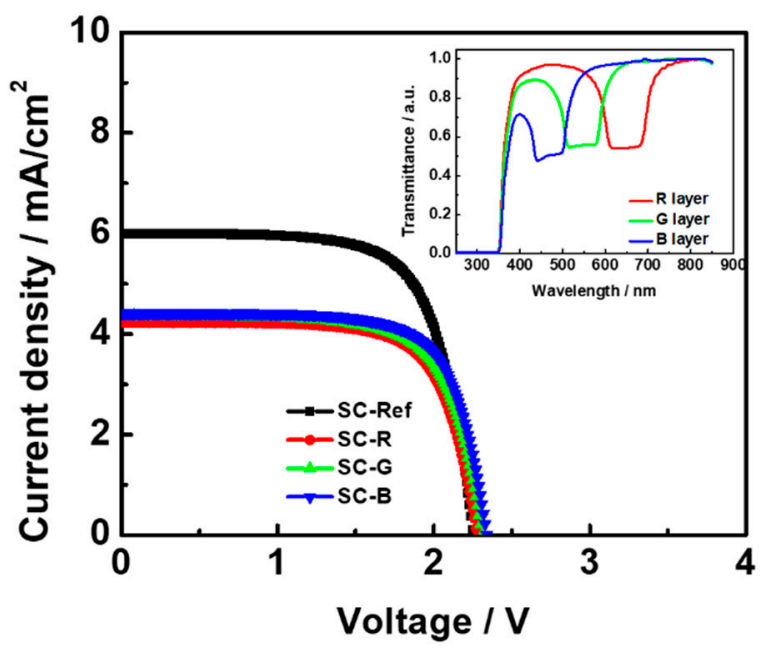

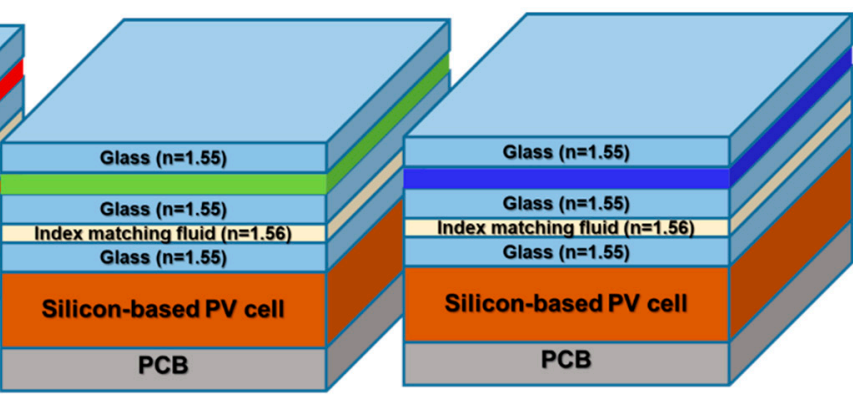

SC-G

SC-B

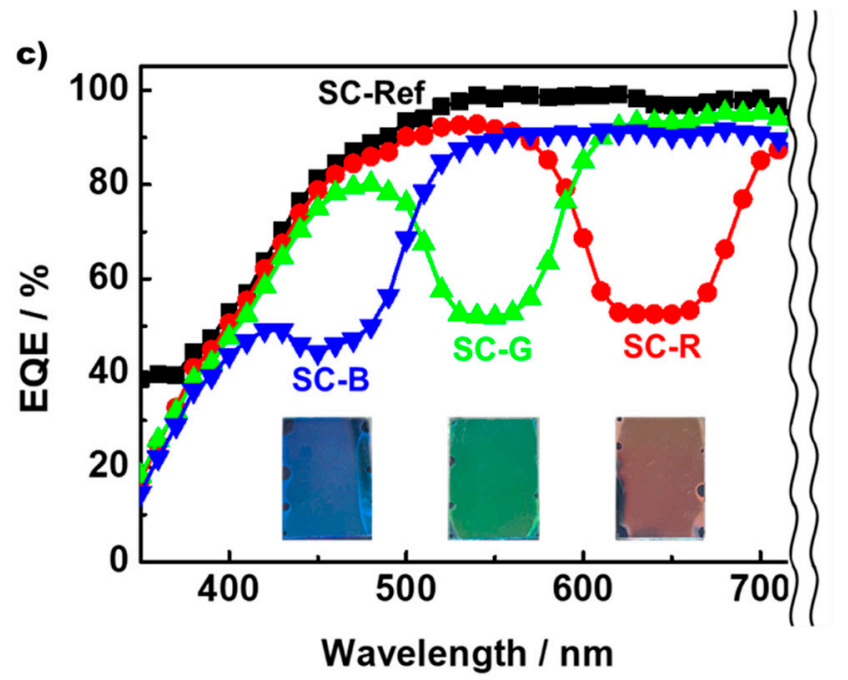

Figure 4. (a) Schematic illustrations of the four modules investigated in this study. (b) Typical current-voltage (J-V) curves of the four modules. Transmittance curves of the fabricated R, G, and B Ch layers are depicted in the inset. (c) EQE spectra of the fabricated R, G, and B Ch layers. Photos of the SC-R, SC-G, and SC-B modules are presented in the inset. The EQE spectra were evaluated using the QE measurement system (Newport), which records $J_{S C}$ by applying a monochromatic light on the samples under ambient conditions. 
Table 1. Performances of the four modules investigated in this study.

\begin{tabular}{ccccccc}
\hline & $\begin{array}{c}V_{O C} \\
{[\mathbf{V}]}\end{array}$ & $\begin{array}{c}J_{S C} \\
{\left[\mathbf{m A} / \mathbf{c m}^{2}\right]}\end{array}$ & $\begin{array}{c}F F \\
{[\%]}\end{array}$ & $\begin{array}{c}\text { PCE } \\
{[\%]}\end{array}$ & $\begin{array}{c}\text { Relative PCE } \\
{[\%]}\end{array}$ & $\begin{array}{c}\text { PCE Loss } \\
{[\%]}\end{array}$ \\
\hline SC-Ref & $2.25 \pm 0.05$ & $4.65 \pm 0.02$ & $70 \pm 1$ & $7.43 \pm 0.22$ & 100 & - \\
\hline SC-R & $2.25 \pm 0.03$ & $3.33 \pm 0.03$ & $71 \pm 1$ & $5.38 \pm 0.14$ & 72 & 28 \\
\hline SC-G & $2.27 \pm 0.02$ & $3.45 \pm 0.02$ & $71 \pm 1$ & $5.60 \pm 0.12$ & 75 & 25 \\
\hline SC-B & $2.22 \pm 0.02$ & $3.57 \pm 0.02$ & $71 \pm 1$ & $5.68 \pm 0.08$ & 77 & 23 \\
\hline
\end{tabular}

Compared to the SC-Ref, the colored SC modules (SC-R, SC-G, and SC-B), with the fabricated R, G, and B Ch layers attached onto their front surfaces, exhibited large PCE losses of $28 \%, 25 \%$, and $23 \%$, respectively. The external quantum efficiency (EQE) spectra presented in Figure 4c indicate that these large PCE losses originate from parasitic losses such as the wide reflectance bandwidth of the Ch layers and strong absorption of the $\mathrm{Ch}$ layers below $350 \mathrm{~nm}$. Thus, the PCE losses can be significantly reduced by simultaneously reducing the parasitic losses. First, a smaller birefringence of the host NLC is required to reduce the bandwidth. The bandwidth $(\Delta \lambda)$ of the selective reflection is denoted as $[18,19]$

$$
\Delta \lambda=\Delta n P
$$

where $n=\left(n_{\mathrm{o}}+n_{\mathrm{e}}\right) / 2$ is the average of the ordinary $\left(n_{\mathrm{o}}\right)$ and extraordinary $\left(n_{\mathrm{e}}\right)$ refractive indices of the uniaxial host NLC mixture, $\Delta n=n_{\mathrm{e}}-n_{\mathrm{o}}$ is the birefringence, and $P$ is the helical pitch. If $P$ is fixed, then the bandwidth can be tuned to a certain extent by controlling the birefringence of the host NLC mixture. Second, the absorption band of the host NLC mixture should be eliminated to reduce the strong absorption below $350 \mathrm{~nm}$ (inset of Figure $4 \mathrm{~b}$ ). That is, the $\pi$-conjugation of the constituent molecules in NLC should be shorter. When the $\mathrm{Ch}$ layer is sandwiched between two glasses owing to the liquidity of the host NLC mixture, which has a low molecular weight, unexpected reflection at the additional glass interfaces affects the device performance. In addition, the form factors (e.g., shape, size, and other hardware designs) are considerably limited. To address these problems, the Ch layers should be fabricated as thin films without liquidity. Therefore, it is favorable that the host NLC possesses a photoreactive polymerizable moiety that aided in the fabrication of a thin $\mathrm{Ch}$ film. Based on our preliminary approaches for optimizing the Ch layers intended for colored SC applications, flexible Ch film integrated-colored SCs with significantly improved PCEs have been developed, and the details will be reported in a separate article.

In summary, a prototype version of colored SCs integrated with liquid crystalline $\mathrm{Ch}$ layers was fabricated, and the device performance was evaluated. Liquid crystalline $\mathrm{Ch}$ layers can selectively reflect light within the reflectance bandwidth owing to spontaneously organized helical structures. This feature renders the $\mathrm{Ch}$ layers as promising candidates for reflective color filters that are applicable in colored SCs. However, the intrinsic shortcomings of the Ch layer, such as the limited reflectance $(\sim 50 \%)$, narrow color gamut due to a wide bandwidth, and viewing angle dependence of the reflective colors, are unfavorable from an esthetic viewpoint. Moreover, attaching the fabricated R, G, and B Ch layers onto the front surface of the SC modules causes large PCE losses originating from parasitic losses such as the wide reflectance bandwidth of the Ch layer and strong absorption of the $\mathrm{Ch}$ layer below $350 \mathrm{~nm}$. Effective strategies for reducing parasitic losses in the Ch layers are suggested in this paper.

Author Contributions: Conceptualization, S.-W.C.; validation, S.B. and D.-S.P.; investigation, S.B. and D.-S.P.; writing-original draft preparation, S.-W.C.; writing-review and editing, S.-W.C.; visualization, S.B.; supervision, S.-W.C.; funding acquisition, S.-W.C. All authors have read and agreed to the published version of the manuscript. 
Funding: This research was funded by the National Research Foundation of Korea (Grant No. 2019R1F1A1058751 and 2020R1A6A1A03048004), and Basic Science Research Capacity Enhancement Project through the Korea Basic Science Institute (National research Facilities and Equipment Center) grant funded by the Ministry of Education (No. 2019R1A6C101052).

Data Availability Statement: Not applicable.

Conflicts of Interest: The authors declare no conflict of interest.

\section{References}

1. Bae, J.-H.; Jung, E.D.; Nam, Y.S.; Kim, B.-C.; Choi, H.-J.; Kim, H.G.; Song, M.H.; Choi, S.-W. Micro-Segregated Liquid Crystal Haze Films for Photovoltaic Applications: A Novel Strategy to Fabricate Haze Films Employing Liquid Crystal Technology. Materials 2018, 11, 2188. [CrossRef] [PubMed]

2. Ballif, C.; Perret-Aebi, L.E.; Lufkin, S.; Rey, E. Integrated thinking for photovoltaics in buildings. Nat. Energy $2018,3,438-442$. [CrossRef]

3. Batmunkh, M.; Zhong, Y.L.; Zhao, H. Recent advances in perovskite-based building-integrated photovoltaics. Adv. Mater. 2020, 32, 2000631. [CrossRef] [PubMed]

4. Yoo, G.Y.; Azmi, R.; Kim, C.; Kim, W.; Min, B.K.; Jang, S.Y.; Do, Y.R. Stable and colorful perovskite solar cells using a nonperiodic $\mathrm{SiO} 2 / \mathrm{Tio} 2$ multi-nanolayer filter. ACS Nano 2019, 13, 10129-10139. [CrossRef]

5. Lee, K.; Kim, N.; Kim, K.; Um, H.D.; Jin, W.; Choi, D.; Park, J.; Park, K.J.; Lee, S.; Seo, K. Neutral-colored transparent crystalline silicon photovoltaics. Joules 2020, 4, 235-246. [CrossRef]

6. Debbarma, M.; Sudhakar, K.; Baredar, P. Comparison of BIPV and BIPVT: A review. Resour.-Effic. Technol. 2017, 3, $263-271$. [CrossRef]

7. Upama, M.B.; Mahmud, M.A.; Yi, H.; Elumalai, N.K.; Conibeer, G.; Wang, D.; Xu, C.; Uddin, A. Low-temperature processed efficient and colourful semitransparent perovskite solar cells for building integration and tandem applications. Org. Electron. 2019, 65, 401-411. [CrossRef]

8. Lu, J.H.; Yu, Y.L.; Chuang, S.R.; Yeh, C.H.; Chen, C.P. High-performance, semitransparent, easily tunable vivid colorful perovskite photovoltaics featuring Ag/Ito/Ag microcavity structures. J. Phys. Chem. C 2016, 120, 4233-4239. [CrossRef]

9. Jung, J.W.; Chueh, C.C.; Jen, A.K.Y. High-Performance Semitransparent Perovskite Solar Cells with $10 \%$ Power Conversion Efficiency and 25\% Average Visible Transmittance Based on Transparent CuSCN as the Hole-Transporting Material. Adv. Energy Mater. 2015, 5, 1500486. [CrossRef]

10. Lee, B.J.; Lahann, L.; Li, Y.; Forrest, S.R. Cost estimates of production scale semitransparent organic photovoltaic modules for building integrated photovoltaics. RCS. Chem. 2020, 11, 5765-5772.

11. Ji, C.; Zhang, Z.; Masuda, T.; Kudo, Y.; Guo, L.J. Vivid-colored silicon solar panels with high efficiency and non-iridescent appearance. Nanoscale Horiz. 2019, 4, 874-880. [CrossRef]

12. Deng, K.; Liu, Z.; Wang, M.; Li, L. Nanoimprinted Grating-Embedded Perovskite Solar Cells with Improved Light Management. Adv. Funct. Mater. 2019, 29, 1900830. [CrossRef]

13. Lee, K.T.; Jang, J.Y.; Zhang, J.; Yang, S.M.; Park, S.; Park, H.J. Highly Efficient Colored Perovskite Solar Cells Integrated with Ultrathin Subwavelength Plasmonic Nanoresonators. Sci. Rep. 2017, 7, 10640. [CrossRef] [PubMed]

14. Hur, S.T.; Lee, B.R.; Gim, M.J.; Park, K.W.; Song, M.H.; Choi, S.W. Liquid-Crystalline Blue Phase Laser with Widely Tunable Wavelength. Adv. Mater. 2013, 35, 3002-3006. [CrossRef] [PubMed]

15. Choi, H.J.; Bae, J.H.; Bae, S.W.; Lee, J.J.; Nishikawa, H.; Araoka, F.; Choi, S.W. Development of a liquid crystal laser using a simple cubic liquid crystalline blue phase platform. RSC Adv. 2019, 9, 32922-32927. [CrossRef]

16. Zheng, Z.-G.; Lu, Y.-Q.; Li, Q. Photoprogrammable mesogenic soft helical architectures: A promising avenue toward future chiro-optics. Adv. Mater. 2020, 32, 1905318. [CrossRef] [PubMed]

17. Hur, S.-T.; Gim, M.-J.; Yoo, H.-J.; Choi, S.-W.; Takezoe, H. Investigation for correlation between elastic constant and thermal stability of liquid crystalline blue phase I. Soft Matter 2011, 7, 8800-8803. [CrossRef]

18. de Gennes, P.G.; Prost, J. The Physics of Liquid Crystals; Oxford Science: Oxford, UK, 1993.

19. Mitov, M.; Dessaud, N. Going beyond the reflectance limit of cholesteric liquid crystals. Nat. Mater. 2006, 5, 361-364. [CrossRef] [PubMed] 